\title{
A publicidade-documentário e a construção discursiva do efeito de real em prol da causa LGBTQ
}

\author{
Leonardo Mozdzenski \\ Universidade Federal de Pernambuco
}

\begin{abstract}
Resumo
Neste artigo, proponho investigar a publicidade contemporânea sexo-diversa, isto é, com temática LGBTQ, atentando para o modo como ela dá voz e visibilidade às subjetividades e aos corpos queer, que subvertem os padrões de gênero e sexualidade. Em especial, minha ênfase recai sobre a construção e as contradições do que denomino publicidade-documentário, constituída a partir da apropriação e transformação de elementos, linguagens e estéticas dos documentários, com o fim de evocar um "efeito de real" nas propagandas. Como exemplos, foram selecionados os filmes publicitários A mágica de Liniker (2016), Toda mulher vale muito (2016) e Absolutas (2017). As discussões teóricas encontram-se fundamentadas em Iribure (2008), Nichols (2016), Melo (2002), Covaleski (2015), Butler (1993), Rocha (2001), Hoff (2016), Bakhtin (2010), entre outros.
\end{abstract}

\section{Palavras-chave:}

Publicidade. Documentário. Engajamento. Causa LGBTQ. Efeito de real.

\section{Introdução'}

Os críticos asseguram que é mero golpe de marketing. Os defensores alegam que, apesar do óbvio interesse financeiro envolvido, o que importa é que uma minoria social - antes acintosamente vilipendiada pelas marcas e pela mídia tradicional - vem sendo cada vez mais visibilizada na publicidade brasileira. $O$ fato é que, bem no centro dessa pujante arena argumentativa, a comunidade formada por lésbicas, gays, bissexuais, travestis, transgêneros, transexuais e queers (LGBTQ) ${ }^{2}$ vem se tornando o público-alvo da vez por parte daquelas empresas que

1 Uma versão preliminar e reduzida deste artigo foi apresentada no IX Propesq PP (USP, 2018).

2 Foge aos limites deste artigo apresentar uma discussão aprofundada sobre a definição de "queer", bem como as implicações teóricas desse termo (para tanto, v. BUTLER, 1993 e 2003). O termo queer está sendo tomado aqui como uma expressão guarda-chuva para denominar as pessoas que são socialmente estigmatizadas por não seguirem o padrão da heterossexualidade ou do binarismo de gêneros (masculino/feminino). A sigla LGBTQ será, pois, preferencialmente empregada ao longo deste trabalho justamente para incluir e visibilizar esse grupo frequentemente marginalizado, além do amplo espectro que diz respeito às sexualidades e às identidades gendéricas dissidentes: intersexuais, assexuais, andróginos, gêneros fluidos, crossdressers, drag queens, drag kings, etc.

Revista Ícone (ISSN 2175-215X) • DOI: 10.34176/icone.v17i2.238965

Recife, Vol. 17, N. 2, 107-124, @ 2019 PPGCOM/UFPE.

Artigo recebido em 1 ago. 2018 e aprovado em 2 fev. 2019. 
querem se mostrar abertamente "pró-diversidade" ou que se "arriscam" ao abraçar causas sociais "polêmicas".

O fenômeno pode ser compreendido como parte da dinâmica do chamado "capitalismo rosa" ou "gaypitalismo" (LILY, 2016), cujas contradições podem ser abordadas sob a ótica de um "ativismo comodificado" (MUKHERJEE E BANET-WEISER, 2012). Por um lado, visando abocanhar uma parcela desse nicho de mercado, as marcas vêm paulatinamente se desvencilhando de preconceitos obsoletos e tentam encontrar formas de se associar ao público LGBTQ - visto como tendo um grande potencial de consumo e uma carência de produtos e serviços direcionados às suas necessidades.

No Brasil, o potencial financeiro do segmento é estimado em US\$ 133 bilhões ao ano, o equivalente a cerca de R 500 bilhões, conforme a Out Leadership, associação internacional de empresas que desenvolve iniciativas voltadas para o público sexo-diverso. Nos EUA, o potencial de consumo é estimado em US\$ 760 bilhões e, na Europa, chega a US\$ 873 bilhões. Ao todo, no mundo, a Out Leadership calcula que o consumidor LGBTQ pode desembolsar vultosos US\$ 3 trilhões para gastar ao ano - o valor do PIB da França ${ }^{3}$.

Por outro lado, entretanto, essa corrida das marcas à procura do pote de pink money no final do arco-íris acabou gerando um grave efeito colateral: o pinkwashing (também chamado de rainbow washing). O termo é derivado de whitewashing ("lavagem branca" ou "embranquecimento"), que indica a prática racista, sobretudo no cinema estadunidense, de escalar atores caucasianos para interpretar personagens fictícios ou históricos de etnia estrangeira. E, por extensão, também é derivado de greenwashing ("lavagem verde" ou "esverdeamento"), que consiste na publicidade enganosa divulgada por uma corporação de forma a apresentar uma imagem pública ambientalmente responsável, quando, na verdade, ela adota ações nocivas ao meio ambiente sob a fachada de um "marketing verde" (FERREIRA E TAVARES, 2017).

Já o pinkwashing ("lavagem rosa”), por sua vez, é constituído por uma ampla variedade de estratégias de marketing e políticas públicas destinadas a promover organizações, produtos, serviços, pessoas e lugares como sendo gay-friendly ("amigáveis a gays" ou "amigayveis", no jargão da comunidade). O objetivo é que sejam percebidos como modernos, abertos, respeitosos e receptivos ao consumidor LGBTQ. O problema surge quando - à semelhança do greenwashing - isso não passa de retórica publicitária para autopromoção de uma reputação marcária progressista, encobrindo práticas discriminatórias de gestão (STARK, 2015). Por exemplo, empresas que se dizem pró-diversidade, mas não contratam travestis e pessoas trans, nem penalizam o assédio moral ou atitudes LGBTQfóbicas de funcionários.

É importante salientar que esse é, sem dúvida, um tema controverso tanto por parte do mercado, quanto entre os ativistas LGBTQ. Uma série de questionamentos pode ser de imediato levantada acerca da alegada maior representatividade midiática da população sexo-diversa, sobretudo quando se trata de vincular sua imagem ao consumo de bens e serviços. Como se dá a construção discursiva dessas identidades - até há pouco tempo disruptivas - nas publicidades brasileiras mainstream? O que é mostrado e o que é silenciado nessas peças? De que modo ocorrem os enfrentamentos retóricos entre marcas e a causa LGBTQ?

Essas são algumas das temáticas que proponho problematizar neste artigo. Mais do que

3 Dados disponíveis em: https://bit.ly/2DFM5eG. Acesso em: 15 nov. 2018. 
oferecer respostas prontas de natureza maniqueísta - a publicidade e a as empresas são "más", o engajamento LGBTQ é "bom", ou vice-versa - ocupo-me aqui em tensionar esses discursos e as relações entre os sujeitos participantes desse embate de vozes sociais. Como suporte teórico-metodológico, lanço mão interdisciplinarmente das teorias discursivo-dialógicas, bem como de conceitos e princípios da teoria queer e dos estudos fílmicos, além de me valer de pesquisas que se dedicam particularmente à análise do domínio publicitário.

Fundamentando-me nesses preceitos, defendo, enfim, que uma das principais estratégias discursivas usadas nas propagandas ${ }^{4}$ para mitigar seu aspecto comercial e avultar um suposto engajamento à causa LGBTQ é a construção do que denomino de publicidade-documentário. Constituída a partir da apropriação e transformação de elementos, linguagens e estéticas dos documentários, a publicidade-documentário protagonizada por membros da comunidade sexo-diversa busca primordialmente evocar um efeito de real ou de verdade, ao dar voz e visibilidade às subjetividades e aos corpos queer, que subvertem os padrões de gênero e sexualidade. E, dessa forma, ressalta-se o valor "positivo" dessas comunicações publicitárias, camuflando-se tensões e resistências.

Como exemplos, serão discutidos três filmes publicitários: A mágica de Liniker (2016), Toda mulher vale muito (2016) e Absolutas (2017).

\section{Visibilidade da população sexo-diversa na publicidade brasileira}

Meio por cento. Não chega nem a atingir esse percentual a representatividade da comunidade LGBTQ na publicidade brasileira no último semestre de 2017. E nos dois últimos anos, raramente esse número foi superado. Os dados são de uma pesquisa realizada pela $\mathrm{TODXS}^{5}$, uma startup social sem fins lucrativos que visa promover a inclusão da população sexo-diversa e o combate à discriminação por orientação sexual ou identidade de gênero.

Entre os anos de 2016 e 2017, a representatividade LGBTQ em peças publicitárias chegou a aumentar de $0,00 \%$ para $0,47 \%$. Mas no segundo semestre do ano passado, essa porcentagem se restringiu a $0,33 \%$. Ademais, além desse baixo desempenho quantitativo, também é importante se levar em conta o aspecto qualitativo dessa representatividade. Isto é, de que modo as pessoas lésbicas, gays, bi, trans e queers estão sendo representadas no universo da propaganda? Em uma investigação de fôlego, Iribure (2008) se propôs a avaliar como as homossexualidades foram retratadas em comerciais televisivos entre os anos de 1979 e 2008. O estudioso chegou à conclusão de que $60 \%$ dos anúncios analisados continham representações estereotipadas desses indivíduos.

$\mathrm{Na}$ contramão dessas tendências desanimadoras, no entanto, tenho observado em minhas pesquisas a emergência de uma proposta diferente de inclusão do público LGBTQ na publicidade brasileira. A princípio, diz respeito ao que Iribure (2008)

4 Neste artigo, utilizo indististamente os termos "publicidade" e "propaganda", na esteira de Droguett e Pompeu (2012, p. 93) e Nelly Carvalho (2014, p. 14).

5 Disponível em: http://bit.ly/2EPnaSv. Acesso em: 14 nov. 2018. O levantamento foi realizado a partir da análise de 5.834 comerciais televisivos e 1.183 anúncios postados no Facebook. 
categoriza como "representações desconstrucionistas". Mas não é só isso. Sob o rótulo de "desconstrucionista", subjaz ainda a tentativa de "agradar essa parcela do mercado [gay], sem desagradar os setores mais conservadores", ou seja, vê-se "o desafio de anunciantes e agências em agradar todos os públicos” (IRIBURE, 2008, p. 240 e 248).

Essa é uma lógica mercadológica caracteristicamente empregada nos comerciais televisivos - principalmente os veiculados na TV aberta, objeto de estudo de Iribure (2008) -, que possuem uma audiência ampla, heterogênea e difusa. Com a internet, as redes sociais digitais e as plataformas de mídia, entretanto, esse cenário vem mostrando novidades. Anunciantes e agências de publicidade vêm gradativamente se libertando da necessidade de "agradar todos os públicos". Essa recente dinâmica mercadológica é responsável por viabilizar, portanto, a crescente produção de peças publicitárias mais criativas e inovadoras, focadas em nichos ou perfis específicos de consumidores, com maior enfoque em questões sociais - que eram antes adstritas a campanhas humanitárias - e com menor preocupação de satisfazer o gosto e os valores massivos das mídias tradicionais (jornais, revistas, rádio e TV).

A inventividade e a originalidade dessas novas propagandas são claramente percebidas no hibridismo entre publicidade e cinema (COVALESKI, 2015), nos "corpos diferentes" que passam a povoá-las (HOFF, 2016), na discussão sobre a ética publicitária (BRAGAGLIA, 2017; GOVATTO, 2007; FEENSTRA, 2014), no investimento corporativo em marketing social (PRINGLE E THOMPSON, 2000; ZENONE, 2006), na contrapublicidade verde (PACHECO RUEDA, 2009; PONTES E TAVARES, 2017), nas ações de responsabilidade social e de políticas de consumo sustentável (COVALESKI, 2015a e 2016; LÓPEZ, 2008; COPELAND, 2014; NOS ALDÁS, 2007; MARTÍN REQUERO, 2008), etc.

E é justamente nesse profícuo caldeirão de possibilidades e imbricações estéticas e artísticas que desponta o que estou denominando de publicidade sexo-diversa. Uma publicidade que põe em cena e visibiliza as subjetividades e os corpos queer, que transgridem os códigos de gênero e sexualidade. A publicidade sexo-diversa não é apenas "desconstrucionista". Ela se pretende expressamente dissidente e contestadora no tocante à heterocoercitividade midiática hegemônica - e, portanto, não objetiva "agradar todos os públicos".

Outro traço marcante verificado na publicidade sexo-diversa é sua busca por produzir uma atmosfera de "autenticidade documental" dos personagens e das situações vivenciadas. Herdeira do chamado New Cinema Queer (NICHOLS, 2005), a publicidade sexo-diversa se funda em um apelo iconoclasta e socialmente engajado. Ainda que evidentemente continuem participando do jogo capitalista neoliberal - afinal, precisam vender um bem ou serviço -, essas propagandas evocam uma visada realista, um compromisso com a "realidade" dos documentários, desconstruindo e desnaturalizando representações identitárias normalizadas, relações de poder, mecanismos de controle social e de ajustamento às convenções cis-heteronormativas.

Desse modo, o próximo ponto a ser aqui desenvolvido diz respeito à definição de documentário e como se dá a construção da voz nesse gênero audiovisual. Em seguida, apresentarei a perspectiva discursiva da produção do efeito de verdade. Finalmente, 
após examinar em maiores detalhes o que estou conceituando de publicidade-documentário, irei exemplificar e aprofundar a discussão a partir de três peças publicitárias protagonizadas por pessoas LGBTQ e que buscam, de alguma forma, "tocar o real" apropriando-me da expressão de Didi-Huberman (2012).

\section{A voz no documentário}

Não é recente o debate entre cineastas, acadêmicos e críticos de cinema à procura de uma definição satisfatória para o documentário, capaz de dar conta da relação desse gênero audiovisual com o real. De acordo com Nichols (2016, p. 30), ainda é usual compreender o documentário como "tratamento criativo da realidade", tal como o definiu John Grierson nos anos 1930. Apesar da vantagem de ser concisa, essa conceituação apresenta imprecisões, já que inúmeros filmes de ficção também retratam fatos históricos, pessoas reais e problematizam questões sociais concretas. Em todo caso, o termo criativo na noção clássica de Grierson já adverte que o documentário "não é uma reprodução da realidade, e sim uma representação do mundo em que vivemos" (NICHOLS, 2016, p. 36).

Para Bernard (2007), os documentários transportam a plateia para novos mundos e experiências através da apresentação de informações factuais sobre pessoas, lugares e eventos reais, geralmente mostrados através de imagens e artefatos autênticos. Ramos (2013, p. 22), por sua vez, entende que o “documentário é uma narrativa com imagens-câmera que estabelece asserções sobre o mundo, na medida em que haja um espectador que receba essa narrativa como asserção sobre o mundo". Já Gauthier (2011) considera que o critério definidor dos documentários é a ausência de atores desempenhando o papel de outra pessoa.

Penafria (2001, p. 1) explicita a dualidade do gênero:

Por um lado, [o documentário] recorre a procedimentos próprios do cinema (escolha de planos, preocupações estéticas de enquadramento, iluminação, montagem, separação das fases de pré-produção, produção, pós-produção, etc.). Por outro lado, enquanto espectadores, exigimos que um documentário, por manter uma relação de grande proximidade com a realidade, deva respeitar um determinado conjunto de convenções: não direcção de actores, uso de cenários naturais, imagens de arquivo, câmera ao ombro, etc. Estes recursos constituem o garante da autenticidade do representado.

Longe da pretensão de esgotar essa controversa e perenal discussão, merece destaque a perspectiva discursiva assumida por Melo (2002) por estabelecer um diálogo mais profícuo com os propósitos deste artigo. A pesquisadora sustenta que a marca característica do documentário "é seu caráter autoral, definido como uma construção singular da realidade, um ponto de vista particular do documentarista em relação ao que é retratado" (MELO, 2002, p. 23, grifos no original). 
E mais: por ser um "discurso pessoal", o documentário - ainda que normalmente priorize a verossimilhança - não se reduz a um mero registro documental, constituindo, com efeito, "um processo ativo de fabricação de valores, significados e conceitos" (MELO, 2002, p. 29). Ainda segundo a estudiosa, "[n]o caso do documentário, sabemos que ele só pode ser construído a partir de outros lugares enunciativos, de outras vozes" (MELO, 2002, p. 34). Daí ser fundamental compreendermos como o documentarista dá voz aos outros personagens e como posiciona sua própria voz em relação ao que eles dizem.

Aprofundando-se essa abordagem discursiva, é conveniente retomarmos brevemente aqui a noção bakhtiniana de vozes sociais. Em Bakhtin (2010), o conceito de vozes sociais se refere a diferentes posicionamentos, opiniões, visões de mundo, posturas ideológicas que permeiam as múltiplas relações dialógicas dos discursos que circulam socialmente e que se materializam nos gêneros discursivos. Por seu turno, esclarece Faraco (2010, p. 84): "O mundo interior é uma arena povoada de vozes sociais em suas múltiplas relações de consonâncias e dissonâncias; e em permanente movimento, já que a interação socioideológica é um contínuo devir".

Desse modo, a noção de voz revela-se bastante útil ao buscarmos apreender os sentidos produzidos nos/pelos documentários. Nessa lógica, ressalta Ramos (2013, p. 23), "[a]s proposições, as asserções, do documentário são enunciadas através de estilos diversos, variando historicamente. Há sempre uma voz que enuncia o documentário, estabelecendo asserções." As vozes dos documentários são, pois, seus traços característicos, demarcando o ponto de vista do documentarista, suas proposições e intervenções como mediador e sua responsabilidade ética na condução desse processo (RAMOS, 2001).

A importância da "voz do cineasta" também é enfatizada por Nichols (2016, p. 29):

É uma voz que emana da totalidade da presença audiovisual de cada filme: a seleção dos planos, o enquadramento dos personagens, a justaposição das cenas, a mixagem dos sons, o uso de títulos e intertítulos - de todas as técnicas por meio das quais o cineasta fala de uma perspectiva distinta sobre um dado assunto e procura persuadir os espectadores a adotar sua perspectiva como se fosse a deles. [...] Buscando uma voz com a qual falar sobre os assuntos que os atraem, os cineastas, tal qual os grandes oradores, precisam falar com o coração de maneiras que se adequem à ocasião e derivem dela.

O pesquisador norte-americano argumenta que, ao representarem o mundo histórico, os documentários constituem uma visão singular do mundo. "A voz do documentário é, portanto, o meio pelo qual esse ponto de vista ou essa perspectiva singular se dá a conhecer" (NICHOLS, 2005, p. 73). Além disso, mesmo que a voz do filme assuma aparentemente um tom de testemunha acrítica, imparcial, objetiva ou desinteressada, ela jamais deixa de oferecer uma opinião sobre o mundo. 
Ao defender uma causa, apresentar uma ideia ou crença, ou transmitir uma opinião, os documentários procuram nos convencer ou persuadir, quer pela força de sua argumentação ou ponto de vista, quer pelo atrativo ou poder de sua voz. "A voz do documentário é a maneira especial de expressar um argumento ou uma perspectiva", atesta Nichols (2005, p. 73). Para tanto, tradicionalmente os documentaristas se empenham em produzir discursivamente o efeito de real em suas obras como estratégia suasória.

Patrick Charaudeau denomina esse fenômeno de "efeito de verdade":

O efeito de verdade está mais para o lado do"acreditar ser verdadeiro" do que para o do "ser verdadeiro". Surge da subjetividade do sujeito em sua relação com o mundo, criando uma adesão ao que pode ser julgado verdadeiro pelo fato de que é compatível com outras pessoas, e se inscreve nas normas de reconhecimento do mundo. Diferentemente do valor de verdade, que se baseia na evidência, o efeito de verdade baseia-se na convicção, e participa de um movimento que se prende a um saber de opinião, a qual só pode ser apreendida empiricamente, através dos textos portadores de julgamentos. $O$ efeito de verdade não existe, pois, fora de um dispositivo enunciativo de influência psicossocial, no qual cada um dos parceiros da troca verbal tenta fazer com que o outro dê sua adesão a seu universo de pensamento e de verdade. O que está em causa aqui não é tanto a busca de uma verdade em si, mas a busca de "credibilidade", isto é, aquilo que determina o "direito à palavra" dos seres que comunicam, e as condições de validade da palavra emitida (CHARAUDEAU, 2010, p. 49, grifos no original).

Trazendo-se essa conceituação para a presente discussão, é possível compreender o documentário tanto como um "texto portador de julgamento", quanto um "dispositivo enunciativo de influência psicossocial”. Por um lado, ele é um texto - em sentido amplo, i.e., abarcando materialidades verbais e não verbais - que opera como um vetor dos posicionamentos, valores, crenças, idiossincrasias, etc., ou seja, do "julgamento" de seu realizador. Por outro lado, a partir de sua obra, o documentarista pretende conquistar a adesão dos espectadores ao mundo retratado na tela como sendo o "real". É justamente essa visada realista do documentário que será apropriada pela publicidade sexo-diversa como estratégia para a construção de uma voz de credibilidade. É o que veremos em seguida.

\section{A publicidade-documentário}

Na contemporaneidade, a publicidade vem assumindo um papel cada vez mais relevante para a instituição, disseminação e cristalização de hábitos, valores e afetividades, ensinando de que modo as pessoas devem se comportar, o que elas devem con- 
sumir e como devem se sentir. Assim, tal como ressalta Baudrillard (2005, p. 264), "a nossa sociedade pensa-se e fala-se como sociedade de consumo. Pelo menos, na medida em que consome, consome-se enquanto sociedade de consumo em ideia. A publicidade é o hino triunfal desta ideia". O hedonismo, a descartabilidade, o egocentrismo e o desperdício são superestimulados e adornados com belas imagens publicitárias para consumo de todos.

De acordo com Rocha (1990), a indústria cultural coloca os indivíduos que a produzem diante de um vasto acervo de ideias, emoções, sensações, escolhas, imposições e práticas. Um intricado universo ideológico é formado pelas representações dessa sociedade que são ali elaboradas, reiteradas e introjetadas pela contínua propagação nos anúncios publicitários. Para o antropólogo, o "discurso publicitário é uma forma de categorizar, classificar, hierarquizar e ordenar tanto o mundo material quanto as relações entre as pessoas, através do consumo" (ROCHA, 2001, p. 25).

Mais do vender produtos, a publicidade vende estilos de vida, sentimentos, visões de mundo. Ela vende uma realidade. "É do jogo de transformações recíprocas entre a vida e as definições da vida presentes no sistema publicitário que se extrai o sentido de 'concretude', a significação de 'verdade' da mensagem dos anúncios', afirma Rocha (1990, p. 100). Dessa maneira, no que diz respeito ao efeito de real nas peças publicitárias, não cabe questionarmos acerca de critérios de verossimilhança ou plausibilidade: "a publicidade [...] não nos ilude: encontra-se para lá do verdadeiro e do falso", pondera Baudrillard (2005, p. 135).

Em outras palavras, na publicidade, o efeito de real também é, tal qual nos documentários, construído discursivamente. A diferença está no "processo de veridição" (CHARAUDEAU, 2010, p. 61). No discurso publicitário, o status da verdade é tradicionalmente da ordem do que há de ser, da promessa, cuja realização só se dará após o consumo do bem ou serviço: a juventude ao passar cremes antirrugas, a aventura ao dirigir um carro, o glamour ao usar um perfume. Aqui não há nada a provar: apela-se para o sonho, o desejo. Já no discurso documental, o status da verdade é da ordem do que já foi, do acontecido: esse é o meu registro sobre algo que ocorreu no mundo, o meu testemunho ou a minha reconstituição dos fatos. Neste caso, a prova se dá pela credibilidade do realizador e sua obra.

Apesar da distinção entre o status de verdade entre esses dois gêneros midiáticos, pode-se constatar que uma das recentes estratégias para intensificação dos efeitos de real na publicidade é lançar mão de configurações, estilos e elementos de gêneros não ficcionais. Assim, torna-se cada vez mais usual no campo publicitário a utilização de reality shows, youtubers, imagens amadoras e vídeos-flagrantes, com o propósito de conferir "autenticidade" ou uma "experiência de realidade" às peças e anúncios. É o que Feldman (2008) chama de "apelo realista", uma tática do audiovisual contemporâneo, que vem progressivamente se acentuando no capitalismo pós-industrial.

É a partir desse referencial, então, que identifico a publicidade-documentário como uma publicidade que "toca o real". Sem deixar de lado os seus propósitos comunicativos originais (seduzir o consumidor, vender para ele um estilo de vida ou uma atitude, e persuadi-lo, em última instância, a adquirir um bem ou serviço), o discurso 
publicitário-documental incorpora, assimila e transforma uma série de recursos técnicos, formatos e estéticas do documentário, sobretudo ao tratar de questões sociais, envolvendo temas sensíveis ou polêmicos - como as ligadas à orientação sexual e identidade de gênero - visando, enfim, provocar no público um "choque do real" (JAGUARIBE, 2007).

É o que com frequência ocorre com as comunicações publicitárias em prol de causas sociais e, em particular, com a publicidade sexo-diversa, tema do próximo tópico.

\section{A voz de engajamento à causa LGBTQ na publicidade-documentário ${ }^{6}$}

Num ambiente despojado, com ares de estúdio improvisado e loft abandonado, a cantora trans Liniker, vocalista da banda de soul e black music Liniker e os Caramelows, nos conta do seu dia a dia e reflete sobre o seu papel como artista e figura pública. "Eu não sou a única bicha preta que tá falando de gênero, de desconstrução. Isso acontece há muito tempo. Eu sou reflexo disso", pondera. Ao fundo, ouvimos versos da canção Zero, de autoria do grupo: "Deixa eu bagunçar você.... Nas imagens, além da cena da entrevista, vemos Liniker se arrumando, se maquiando e olhando pensativa para a cidade. Trechos de sua fala também surgem destacados na tela (como "olho", no jornalismo impresso). Ao final do filme, Liniker se junta à sua trupe para cantar a debochada Vocêfez merda.

Sentada diante de uma penteadeira em um quarto charmoso e bem decorado, a modelo cearense Valentina Sampaio desliza suavemente as mãos pelo seu corpo, seca e escova seus cabelos, usa pincel de blush e batom e, por fim, confere orgulhosa o resultado no espelho. Em off, Valentina declara: "Eu amo ser mulher. É muito bom a gente se aceitar, se amar, reconhecer o nosso valor. [...] Esse é o meu primeiro Dia da Mulher. Oficialmente." A cena se encerra com a jovem posicionada em um fundo branco, dizendo: "Tô pronta". Um forte clarão aparece na tela, como um flash fotográfico, seguido do texto escrito: "Valentina é uma mulher transgênera. E esta é a foto da sua nova carteira de identidade, finalmente como Valentina". Uma foto $3 \times 4$ da modelo é mostrada no fim do vídeo.

Ambientado em múltiplos cenários, o curta inicia como uma mescla de videoclipe e videoarte, mostrando a performance da cantora, rapper e atriz transexual Linn da Quebrada numa versão remixada da música Submissa do $7^{\circ}$ dia. Logo na abertura, a "artista multimídia e bixa travesty" dispara: "Olha só, doutor, saca só que genial: sabe a minha identidade? Nada a ver com o genital!”. O filme prossegue intercalando cenas registradas em diferentes formatos e com efeitos de pós-produção, no quarto, na boate, no supermercado, no restaurante, nas ruas, etc., arrematadas com o manifesto: "Ser bicha, trava, sapatão, trans, bissexual é também poder resistir". Nos créditos finais, 6 As citações dos três primeiros parágrafos deste tópico estão propositalmente sem as respectivas referências, que serão reveladas logo a seguir.

7 Essa é autodescrição da cantora em seu Facebook. Disponível em: http://bit.ly/2n0xZdb. Acesso em: 14 nov. 2018. 
depoimentos filmados em preto e branco da cantora e de Raquel Virgínia e Assucena Assucena (vocalistas trans do grupo As Bahias e a Cozinha Mineira, que também participam da produção) discutem a importância e o valor da visibilidade de artistas travestis num mundo demasiadamente machista e transfóbico.

A princípio, as três obras descritas anteriormente poderiam facilmente ser percebidas como documentários sobre a comunidade LGBTQ ou sobre o empoderamento de pessoas trans, não fosse por uma particularidade inescapável: trata-se de publicidades da Axe, da L'Oréal e da Absolut, respectivamente'.

Intitulada A mágica de Liniker (2016), a primeira peça chegou a ser divulgada como um "minidocumentário" e faz parte do reposicionamento dos desodorantes masculinos Axe, buscando eliminar a imagem machista associada à marca (Figura 1).

O segundo comercial se chama Toda mulher vale muito (2016) e pretende ser um gesto inclusivo da empresa de cosméticos L'Oréal para abranger não só mulheres cis, mas também mulheres trans em seu discurso em comemoração ao Dia da Mulher (Figuras 2 e 3).

Finalmente, Absolutas (2017), o terceiro anúncio, foi produzido pela vodca Absolut e integra o projeto global Absolut Art Resistance, que reúne manifestações artísticas pautadas por embates político-sociais desde os anos 1970, ratificando o histórico posicionamento da marca nesse campo de atuação (Figura 4).

A preferência dessas publicidades por travar relações intertextuais tipológicas com o gênero documentário não é evidentemente gratuita ou acidental (COVALESKI, 2015). Nichols (2005) lembra que, desde a década de 1970, os documentários foram um relevante espaço para dar voz a gays e lésbicas, que contavam suas experiências pessoais de descoberta da própria sexualidade e da resistência social que sofreram.

Em geral, eram filmes comprometidos com a política de identidade, voltados para a autopercepção e autodescrição feitas pelos respectivos membros da comunidade, sem a opinião de especialistas ou de autoridades, analogamente às peças $A$ mágica de Liniker e Toda mulher vale muito. Alguns, inclusive, usavam "o estilo de edição dos vídeos musicais para ratificar a construção ativa do desejo homoerótico", afirma Nichols (2005, p. 199), de modo semelhante ao comercial Absolutas. Por fim, Nichols (2005, p. 201) sintetiza a importância social e política dessas obras:

A dimensão política de documentários sobre questões de se-
xualidade e gênero [...] une um modo enfaticamente performá-
tico de representação documental às questões de experiência
pessoal e desejo que se expandem, por implicação, para ques-
tões mais abrangentes de diferença, igualdade e não discrimina-
ção. Como muitas outras obras, eles contribuem para a constru-
ção social de uma identidade comum entre membros de uma
dada comunidade. Dão visibilidade social a experiências antes

8 Disponíveis em: http://bit.ly/2DqKuWq, http://bit.ly/2Dz06dY e http://bit.ly/2mY4ADS, nessa ordem. Acesso em: 14 nov. 2018.

9 Disponível em: http://bit.ly/2DDvHLt. Acesso em: 14 nov. 2018. 

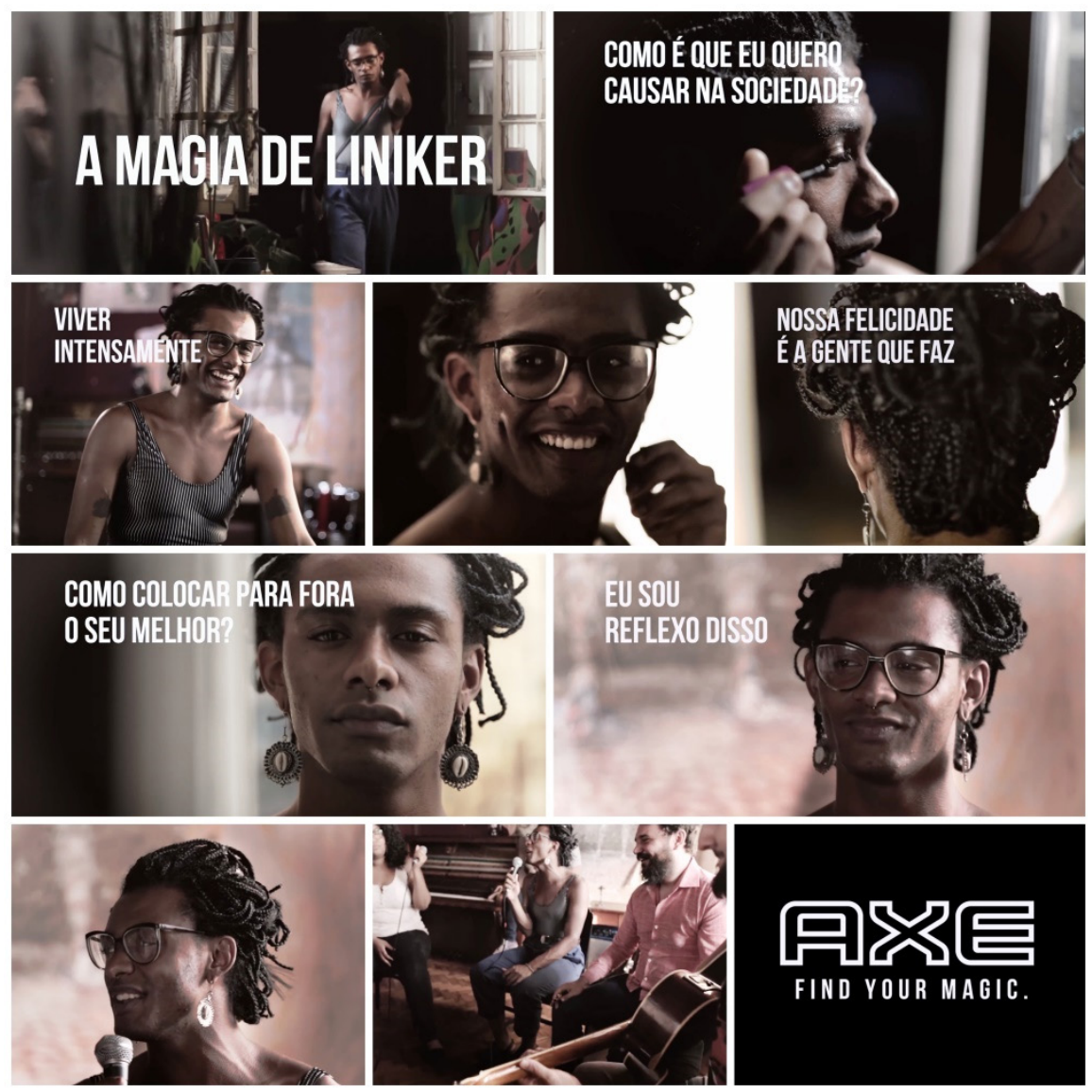

Figura 1 - Cenas do comercial A mágica de Liniker, da Axe (2016). Canal do YouTube AXEbr.

tratadas como exclusivas ou principalmente pessoais; atestam uma comunhão de experiência e as formas de luta necessárias para superar o estereótipo, a discriminação e a intolerância. $A$ voz política desses documentários encarna as perspectivas e visões de comunidades que compartilham uma história de exclusão e um objetivo de transformação social. (Grifos acrescentados.)

Vale sublinhar, contudo, que, apesar do seu inegável mérito de visibilizar e dar protagonismo às pessoas LGBTQ, a publicidade-documentário sexo-diversa é atravessada por uma contradição imanente. Por um lado, ela busca "tocar o real", saindo do lugar-comum dos ditames publicitários modelares heterocompulsórios e pondo em evidência vozes queer, suas subjetividades, corpos, estéticas, valores e afetividades "reais", que põem em xeque as convenções de gênero e de sexualidade. Com isso, essas peças acabam burlando a hiporrepresentação midiática e publicitária dessa coletivida- 


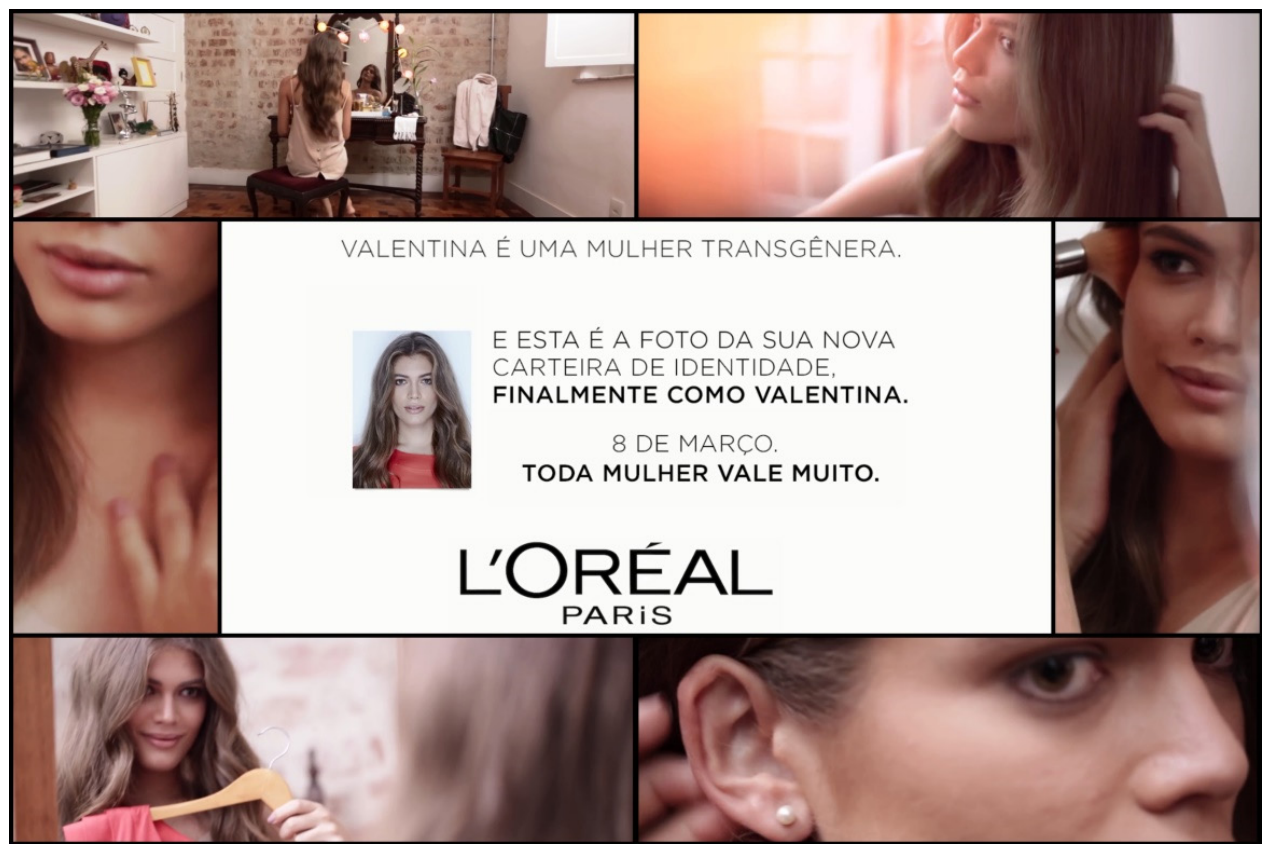

Figura 2 - Cenas do comercial Toda mulher vale muito, da L'Oréal (2016). Canal do YouTube Agência WMcCann BR.

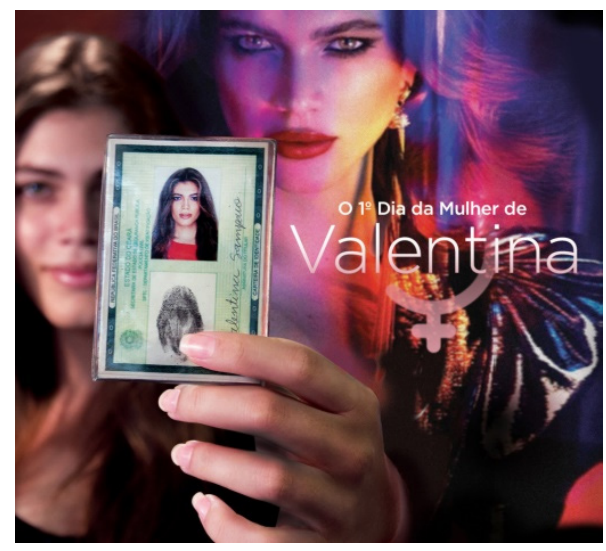

Figura 3 - Publicidade do $1^{\circ}$ Dia da Mulher de Valentina, da L'Oréal (2016). Canal do YouTube Agência WMcCann BR. 

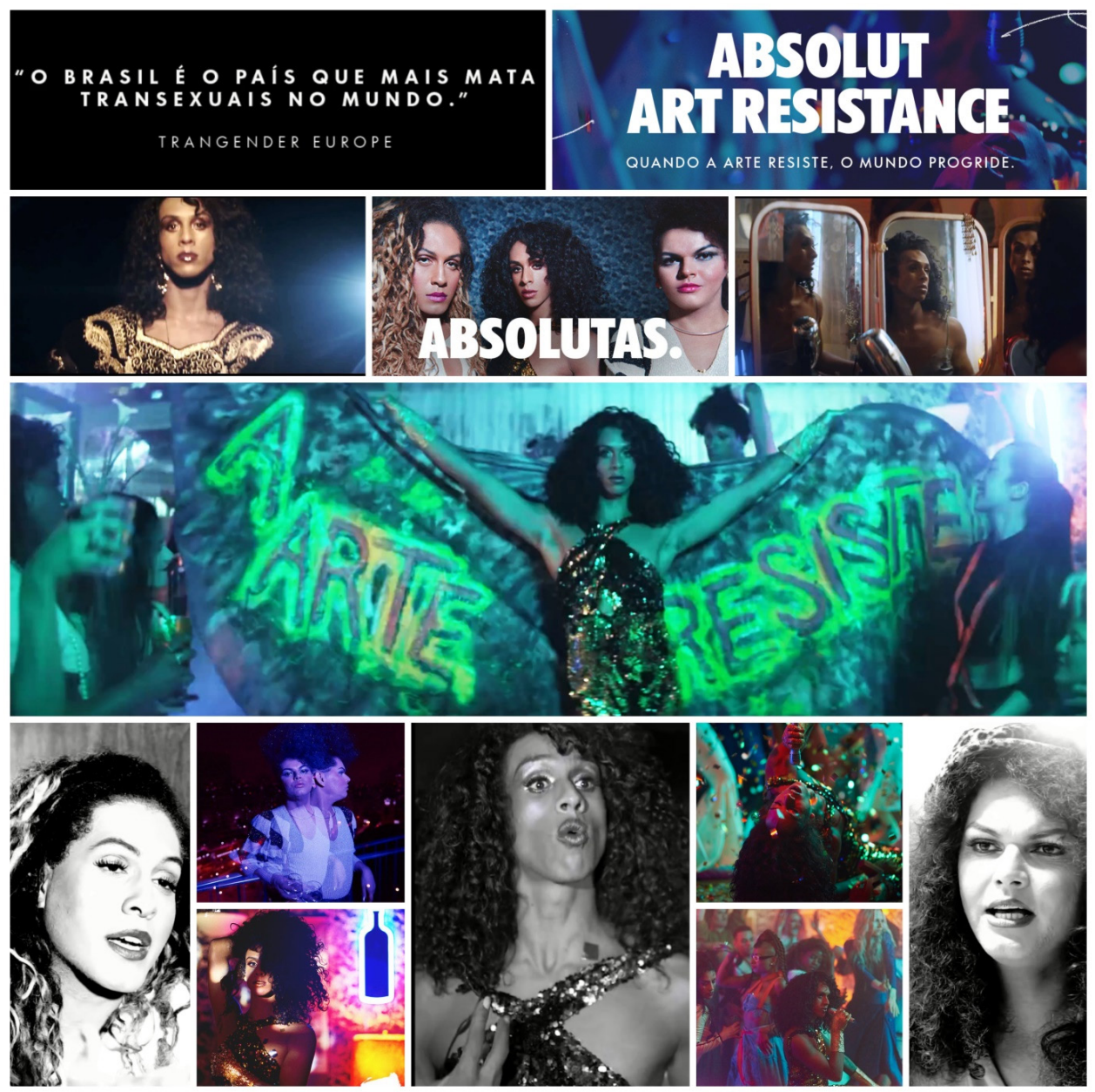

Figura 4 - Cenas do comercial Absolutas, da Absolut (2017). Canal do YouTube AbsolutBrasil.

de sexo-gendérica disruptiva.

Por outro lado, o domínio publicitário é uma peça-chave na engrenagem do capitalismo e consiste em uma das principais estratégias de disseminação e longevidade da ideologia neoliberal. Desse modo, a publicidade sexo-diversa está concomitantemente servindo como catalisador dos processos de comoditização e espetacularização das vivências do "real" da/na comunidade LGBTQ. E, assim - enquanto dispositivo disciplinar e de controle (DOMINGUES, 2016) -, a publicidade finda por promover, no limite, a normalização e docilização dos corpos queer (WEEKS, 2000) e a produtificação da causa LGBTQ.

Nesse sentido, a própria existência de uma publicidade que veicula/produz uma voz de engajamento à causa LGBTQ pode, inclusive, ser encarada como um contras- 
senso. A teoria queer faz parte - juntamente com os estudos pós-coloniais - das chamadas "teorias subalternas", que tecem uma crítica sistemática aos discursos hegemônicos na cultura ocidental, ao neoliberalismo e à cultura gay integracionista e mercadorizada (PRECIADO, 2007). Já a publicidade, ao contrário, opera na direção de transformar tudo em mercadorias vendáveis.

Esse conflito de interesses (queer x mercado) faz emergir um fenômeno paradoxal a que denomino de publicidade armarizada, caracterizada pela presença de personagens homossexuais "dentro do armário, discretos e fora do meio". A publicidade armarizada até pode ser considerada "desconstrucionista" (na acepção de IRIBURE, 2008), já que realmente não apela para estereótipos ou para o escárnio ao representar gays e lésbicas. Em contrapartida, ela naturaliza e legitima a homo-higienização simbólica na propaganda, ao se limitar a retratar homens gays viris e lésbicas femininas, e desde que não haja manifestação explícita de afetos mais íntimos nem insinuações sexuais.

Compreendo como plumofóbico ${ }^{10}$ esse tipo de imagem publicitária higienizada de gays e lésbicas, o qual implica o apagamento de trans, queers e outras dissidências radicais menos categorizáveis. O melhor exemplo recente de publicidade armarizada foi o comercial do Dia dos Namorados d'O Boticário de $2015^{11}$, em que dois casais homossexuais "discretos" se abraçavam assepticamente em recintos fechados e privados, ao contrário dos casais hétero, trocando presentes num restaurante ou rodopiando numa praça. Uma clara tentativa de parecer inclusivo e pró-diversidade, sem ofender os valores da família tradicional brasileira. Nada mais distante do real.

\section{Considerações Finais}

No ensaio Quando as imagens tocam o real, Didi-Huberman (2012, p. 209) nos propõe as seguintes questões ao nos deparamos com as inúmeras imagens que pululam em nosso universo estético, técnico, cotidiano, político, histórico: "a que tipo de conhecimento pode dar lugar a imagem? Que tipo de contribuição ao conhecimento histórico é capaz de aportar esse 'conhecimento pela imagem'?". No fundo, foram essas as perguntas que nortearam a minha investigação sobre a publicidade-documentário sexo-diversa. Que realidades, vozes e subjetividades essa publicidade dá a conhecer e como isso se sucede? Que contribuição social, política, cultural e histórica ela propicia? E que contradições relacionadas à comoditização da causa LGBTQ ela veicula?

Nas narrativas publicitárias, as representações genuinamente inclusivas das sexualidades estigmatizadas são fundamentais para proporcionar protagonismo e sentimento de pertencimento coletivo. Não resta dúvida de que a presença realista - i.e., não estereotipada, não caricaturada e não pautada pelo padrão heterossexista - de lésbicas, gays, bi, trans e queers na mídia constitui um caminho importante para a visibilidade

10 A "plumofobia" (DURÁN, 2017) é o termo utilizado para designar o preconceito e a minoritização dentro da própria comunidade LGBTQ, quando aqueles membros considerados menos valorizados ou menos compatíveis com o homonormativismo (e.g., homens gays afeminados, lésbicas masculinizadas, travestis, pessoas com gênero fluido, etc.) são vítimas de discriminação por seus pares.

11 Disponível em: http://bit.ly/1FMeWYr. Acesso em: 14 nov. 2018. 
e legitimação desse público. Portanto, ainda que haja embates entre representatividade de minorias e oportunismo mercadológico, é inegável que a mídia e a publicidade são espaços de poder, e ocupar esses espaços legitima corpos e identidades antes marginalizados e restritos a bolhas guetificadas.

Assim, embora peças sexo-diversas tais como os anúncios exemplificados anteriormente integrem e impulsionem a engrenagem capitalista neoliberal, revela-se flagrante a fratura no cânone publicitário provocada por essas propagandas efetivamente desarmarizadas - "lacrativas", "pintosas", "enviadadas", "bafônicas", "babadeiras", "close certo", "translésbichas" e tudo o mais que o pajubá puder expressar. Em outras palavras, se é fato que os recentes posicionamentos marcários tendem a produtificar a causa LGBTQ, em contrapartida, eles também promovem o deslizamento de sentidos e a circulação de novos discursos publicitários menos cis-heteroparadigmáticos, oferecendo ao consumidor outras variedades de narrativas e de sujeitos às quais ele não estava habituado.

Sobretudo diante do crescente conservadorismo na política, na mídia e na sociedade como um todo, é imprescindível refletirmos sobre temáticas como a desnaturalização da sexualidade, o rompimento dos binarismos de gênero, a problematização dos padrões hegemônicos cis-heteronormativos. E sempre buscando compreender e abarcar a flexibilidade, a pluralidade, o deslocamento, os atravessamentos e as fissuras das posições discursivas assumidas pelos indivíduos enquanto sujeitos sexualizados/ genderificados, conferindo especial atenção aos grupos de maior vulnerabilidade e às dissidências sexuais e de gênero formadas pela comunidade LGBTQ.

\section{Referências}

BAKHTIN, M. Questões de literatura e estética: a teoria do romance. 6.ed. São Paulo: Hucitec, 2010.

BAUDRILLARD, J. A sociedade de consumo. Lisboa: Edições 70, 2005.

BERNARD, S.C. Documentary storytelling: making stronger and more dramatic nonfiction films. 2.ed. Burlington: Elsevier, 2007.

BRAGAGLIA, A.P. (Org.). Ética na publicidade: por uma nova sociedade de consumo. Rio de Janeiro: Multifoco, 2017.

BUTLER, J. Bodies that matter: on the discursive limits of sex. New York: Routledge, 1993.

. Problemas de gênero: feminismo e subversão da identidade. Rio de Janeiro: Civilização Brasileira, 2003.

CARVALHO, N. Linguagem da publicidade. Recife, Ed. UFPE, 2014.

CHARAUDEAU, P. Discurso das mídias. 2.ed. São Paulo: Contexto, 2010.

COVALESKI, R. Cinema e publicidade: intertextos e hibridismos. Rio de Janeiro: Confraria do Vento, 2015.

Narrativa como estratégia publicitária para ações de responsabilidade social e de

políticas de consumo sustentável. In: CASTRO, M.G.; CAIRES, C.S.; RIBAS, D.; PALINHOS, 
J. (Eds.). Cartografia das fronteiras da narrativa audiovisual. Porto: Universidade Católica Editora, 2016. p. 60-69.

. Responsabilidade, Solidariedade e Sustentabilidade: causas sociais no Cannes Lions Innovation Festival 2015. In: XXXVIII Congresso Brasileiro de Ciências da Comunicação, 2015, Rio de Janeiro. Anais... Rio de Janeiro: UFRJ, 2015a.

DIDI-HUBERMAN, G. Quando as imagens tocam o real. Pós, v. 2, n. 4, p. 2014-219, nov. 2012.

DOMINGUES, I. Publicidade de controle: consumo, cibernética, vigilância e poder. Porto Alegre: Sulina, 2016.

DROGUETT, J.G.D.; POMPEU, B. Dicionário técnico de comunicação publicitária: conceitos fundamentais. São Paulo: Cia. dos Livros, 2012.

DURÁN, A. Plumofobia, racismo y discriminación en las apps de ligue gay. Vice, 13/02/2017. Disponível em: http://bit.ly/2CLga7D. Acesso em: 14 nov. 2018.

FARACO, C. Linguagem e diálogo: as idéias linguísticas do Círculo de Bakhtin. São Paulo: Parábola, 2010.

FEENSTRA, R.A. Ética de la publicidad: retos en la era digital. Madrid: Dykinson, 2014. FELDMAN, I. O apelo realista. Famecos, n. 36, p. 61-68, ago. 2008.

FERREIRA, G.G.T.; TAVARES, F. Natureza líquida: as modelagens marcárias e a publicidade verde. Curitiba: Appris, 2017.

GAUTHIER, G. O documentário: um outro cinema. Campinas, SP: Papirus, 2011.

GOVATTO, A.C.M. Propaganda responsável: é o que todo anunciante deve fazer. São Paulo: Senac, 2007.

HOFF, T. Comunicação publicitária: dos regimes de visibilidade do corpo diferente às biossociabilidades do consumo. In: (Org.). Corpos discursivos: dos regimes de visibilidade às biossociabilidades do consumo. Recife: Ed. UFPE, 2016. p. 19-40.

IRIBURE, A. As representações das homossexualidades na publicidade e propaganda veiculadas na televisão brasileira: um olhar contemporâneo das últimas três décadas. 2008. 309f. Tese (Doutorado em Comunicação e Informação) - Faculdade de Biblioteconomia e Comunicação, UFRGS, Porto Alegre, 2008.

JAGUARIBE, B. O choque do real: estética, mídia, cultura. Rio de Janeiro: Rocco, 2007. LILY, S. Adiós, Chueca - Memorias del gaypitalismo: creando la marca gay. Madrid: Askal, 2016.

LÓPEZ, A.L. Comunicación con sentido: consumo responsable. In: MARTÍN, L.R. (Org.). Publicidad y consumo: nuevas modas, viejas causas y valores sociales. Sevilla: Comunicación Social, 2008. p. 64-85.

MARTÍN REQUERO, M.I. Comunicación con causa: las causas de la publicidad. In: MARTÍN, L.R. (Org.). Publicidad y consumo: nuevas modas, viejas causas y valores sociales. Sevilla: Comunicación Social, 2008. p. 13-41.

MELO, C.T.V. O documentário como gênero audiovisual. Comun. Inf., v. 5, n. 1/2, p. 25-40, 
jan./dez. 2002.

MUKHERJEE, R.; BANET-WEISER, S. (Eds.). Commodity activism: cultural resistance in neoliberal times. New York: New York University Press, 2012.

NICHOLS, B. Introdução do documentário. Campinas: Papirus, 2005. . Introdução do documentário: nova edição. 6.ed. Campinas: Papirus, 2016.

NOS ALDÁS, E. Lenguaje publicitario y discursos solidarios: eficacia publicitaria, ¿eficacia cultural? Barcelona: Icaria, 2007.

PACHECO RUEDA, M. El discurso disidente de la contrapublicidad verde. Pensar la Publicidad, v. III, n. 1, p. 55-82, 2009.

PENAFRIA, M. O ponto de vista no filme documentário. Covilhã: Universidade da Beira Interior, 2001. Disponível em: http://bit.ly/2Bfvt8d. Acesso em: 14 nov. 2018.

PONTES, F; TAVARES, F. Ecosofia das marcas: as três ecologias na publicidade verde. Curitiba: Appris, 2017.

PRECIADO, P.B. Entrevista a Jesús Carrillo. Cadernos Pagu, v. 28, p. 375-405, 2007.

PRINGLE, H.; THOMPSON, M. Marketing social. São Paulo: Makron Books, 2000.

RAMOS, F.P. Mas afinal... o que é mesmo documentário? 2.ed. São Paulo: Senac, 2013.

. O que é documentário? In: RAMOS, F.P.; CATANI, A. (Orgs.). Estudos de Cinema SOCINE 2000. Porto Alegre: Sulina, 2001. p. 192-207.

ROCHA, E. A mulher, o corpo e o silêncio: a identidade feminina nos anúncios publicitários. Alceu, v. 2, n. 3, p. 15-39, jul./dez. 2001.

. Magia e capitalismo: um estudo antropológico da publicidade. São Paulo: Brasiliense, 1990.

STARK, J. 'Pink washing': marketing stunt or corporate revolution? The Sydney Morning Herald, 6 jun. 2015. Disponível em: https://bit.ly/2OLKW6D. Acesso em: 14 nov. 2018.

WEEKS, J. O corpo e a sexualidade. In: LOURO, G.L. (Org.). O corpo educado: pedagogias da sexualidade. 2.ed. Belo Horizonte: Autêntica, 2000. p. 35-82.

ZENONE, L.C. Marketing social. São Paulo: Thomson Learning, 2006. 


\title{
The advertising documentary and the discursive construction of the reality effect in favor of the LGBTQ cause
}

\begin{abstract}
In this article, I propose to investigate contemporary sex-diverse advertising, that is, with LGBTQ themes, paying attention to the way it gives voice and visibility to the subjectivities and queer bodies, which subvert the standards of gender and sexuality. In particular, my emphasis is on the construction and contradictions of what I call documentary advertising, which is constituted by appropriating and transforming elements, languages and aesthetics of documentaries, in order to evoke a "reality effect" in advertisements. As examples, I selected the advertising films The magic of Liniker (2016), Every woman is worthy (2016) and The Absolutes (2017). The theoretical discussions are based on Iribure (2008), Nichols (2016), Melo (2002), Covaleski (2015), Butler (1993), Rocha (2001), Hoff (2016), Bakhtin (2010), etc.
\end{abstract}

\section{Keywords}

Advertising. Documentary film. Engagement. LGBTQ cause. Reality effect.

\section{Sobre o autor}

Leonardo Mozdzenski. Doutor em Linguística pelo Programa de Pós-Graduação em Letras da Universidade Federal de Pernambuco e, atualmente, doutorando em Comunicação pelo Programa de Pós-Graduação em Comunicação da mesma instituição. Licenciou-se em Letras (Português/Inglês) e graduou-se em Economia pela UFPE. Possui especialização em Leitura, Compreensão \& Produção Textual e mestrado em Linguística também pela mesma Universidade. leo_moz@yahoo.com.br 